\title{
Immobilization of Aspergillus fumigatus colonies in a soft agar matrix allows visualization of A549 cell detachment and death
}

\author{
P. DALY \& K. KAVANAGH \\ Medical Mycology Unit, Department of Biology, National University of Ireland Maynooth, Co. Kildare, Ireland
}

\begin{abstract}
A model to examine the effects of proliferating Aspergillus fumigatus ATCC 26933 colonies embedded in a thin layer of soft agar on a monolayer of A549 cells was developed and enabled an investigation of the response of cultured cells to fungal growth. This model simulates the conditions on the respiratory surface in patients with invasive aspergillosis and also in the mucus secretions of cystic fibrosis patients with allergic bronchopulmonary aspergillosis. Conidia of A. fumigatus adhering to A549 cells were immobilized in a thin layer of soft agar $(0 \cdot 6 \%(\mathrm{w} / \mathrm{v}))$ and allowed to germinate at $37{ }^{\circ} \mathrm{C}$. Fungal colonies greater than $5 \mathrm{~mm}$ in diameter caused roundingup and detachment of A549 cells underneath the colony and towards the hyphal tips. As the fungal colony diameter increased, cell detachment occurred ahead of the hyphal tips. Cells detached for short periods (less than $6 \mathrm{~h}$ ) showed no annexin-V $(\mathrm{AV})$ or propidium iodide (PI) staining, suggesting no externalization of phosphatidylserine and an intact plasma membrane. Cells that had detached for periods greater than $6 \mathrm{~h}$ were positive for $\mathrm{AV}$ and PI indicating the rupture of the plasma membrane and cell death by necrosis. Chemical extraction and separation by thin layer chromatography of agar from zones of cell detachment around fungal colonies revealed the presence of three compounds that may play a role in inducing cell death.
\end{abstract}

Keywords A549 cells, apoptosis, Aspergillus fumigatus, necrosis

\section{Introduction}

Aspergillus fumigatus is an opportunistic fungal pathogen capable of infecting the lung in those with preexisting lung damage or disease. The incidence of aspergillosis has increased dramatically in recent years due, in part, to the use of aggressive immunosuppressive therapy causing prolonged neutropenia [1] and is second only to that of Candida infections but produces greater mortality rates $[2,3]$.

The actual mechanisms by which $A$. fumigatus colonizes the respiratory tract are not clearly understood. It is believed that a combination of host factors

Correspondence: Dr Kevin Kavanagh, Medical Mycology Unit, Department of Biology, NUI Maynooth, Co. Kildare, Ireland. Tel.: +353-1-708 3859; fax: +353-1-708 3845; e-mail: Kevin. Kavanagh@may.ie. (e.g. immunosuppression, impaired mucociliary clearance) facilitates the growth of the fungus and also that the secretion of enzymes and toxins by the fungus aids colonization of pulmonary tissue [4,5]. The adherence of conidia to respiratory epithelial tissues is a crucial step in colonization of the lung [6] and fibrinogen, fibronectin, complement and laminin have been identified as ligands for A. fumigatus conidia [7].

The production and secretion of enzymes (e.g. elastase) and toxins (e.g. gliotoxin, fumagillin) into surrounding tissues by the proliferating fungus is regarded as an important virulence attribute and may facilitate fungal growth in the lung [8]. Gliotoxin is the main toxin produced by $A$. fumigatus. Others include helvolic acid, fumigatin and fumagillin $[4,9,10]$.

Conventional assays to study the effects of fungal enzymes and toxins on cultured cells rely upon culturing 
the fungus in liquid growth medium and applying either conditioned medium or extracts from such medium directly to cells $[2,4]$. These methods have a number of disadvantages since in cases of invasive aspergillosis or allergic bronchopulmonary aspergillosis (ABPA) the enzymes and toxins produced by the fungus do not diffuse into a liquid environment but are concentrated by the nature of the surrounding milieu in the vicinity of fungal growth [8]. Consequently, pulmonary tissue adjacent to colonies of $A$. fumigatus experiences greater concentrations of enzymes and toxins than tissue removed from the site of infection. Soft agar assays have been used to ascertain the effects of growth factors on RPMI 2650 cells. They are advantageous in providing a matrix for colony formation that is absent in a liquid environment [11]. The soft agar assay developed here allows the localization of secreted products in the vicinity of the fungal colony and facilitates examination of the response of cultured cells. This system may offer a means of simulating in vitro the response of cells to the secretion of enzymes and toxins by $A$. fumigatus in cases of invasive aspergillosis or ABPA.

\section{Materials and methods}

Isolation of conidia

A. fumigatus ATCC 26933 (originally isolated from a case of human pulmonary aspergillosis) was obtained from the American Type Culture Collection (Manasas, VA, USA). A. fumigatus 26933 conidia were isolated from malt extract agar (MEA) plates $(2 \%(\mathrm{w} / \mathrm{v})$ malt extract (Oxoid, Basingstoke, England), 2\% (w/v) glucose (Riedel de Haën, Germany), $0 \cdot 1 \%$ (w/v) peptone (Oxoid) and 2\% (w/v) agar (Difco, Detroit, MI, USA)) after growth for 7 days at $37{ }^{\circ} \mathrm{C}$ using a $0.01 \%$ (v/v) Tween 80 solution (Merck, München, Germany). Conidia were washed three times with phosphatebuffered saline (PBS) and re-suspended in $10 \mathrm{ml}$ of minimal essential medium (MEM) (Sigma Chemical Co., St Louis, MO, USA) containing $5 \%(\mathrm{v} / \mathrm{v})$ foetal calf serum (FCS) (Gibco, Paisley, Scotland) and 1\% (v/v) L-glutamine (Gibco) at a concentration of $1.8 \times 10^{2}$ conidia $\mathrm{ml}^{-1}$ and used immediately in the soft agar assay. Conidia were enumerated following suitable dilution in PBS with an haemocytometer.

\section{Cell culture}

The A549 cell line is an adherent human lung carcinoma with type II alveolar epithelial cell properties [12]. A549 cells were cultured in MEM supplemented with 5\% (v/v) FCS and $1 \%(\mathrm{v} / \mathrm{v})$ L-glutamine. Cells were grown in $80-\mathrm{cm}^{2}$ tissue culture flasks (Nunc, Copenhagen, Den- mark) at $37{ }^{\circ} \mathrm{C}$ and $5 \% \mathrm{CO}_{2}$ in a humidified atmosphere. Cells were routinely sub-cultured after trypsinization every 3-4 days.

Cells for the soft agar assay were first trypsinized, washed with PBS and re-suspended in MEM at a final cell density of $5 \times 10^{5} \mathrm{ml}^{-1} ; 25-\mathrm{cm}^{2}$ flasks (Nunc) were seeded with $5 \mathrm{ml}$ of this suspension and incubated for $24 \mathrm{~h}$ at $37^{\circ} \mathrm{C}$ in a humidified $5 \% \mathrm{CO}_{2}$ incubator to facilitate cell attachment.

\section{Soft agar assay}

The soft agar assay developed here was a modification of the method described by Carey et al. [11]. Growth medium was decanted from confluent cultures of A549 cells in $25-\mathrm{cm}^{2}$ flasks (Nunc) and replaced with $5 \mathrm{ml}$ MEM containing $1.8 \times 10^{2} \mathrm{ml}^{-1}$ conidia of $A$. fumigatus. These were incubated for $2 \mathrm{~h}$ at $37{ }^{\circ} \mathrm{C}$ to facilitate conidia adherence to cells. The ratio of $1.8 \times 10^{2}$ conidia to $5 \times 10^{5}$ A549 cells was chosen following preliminary experimentation which showed that $25-30 \%$ of conidia would adhere during the incubation period. This subsequently resulted in the growth of approximately 50 clearly distinguishable $A$. fumigatus colonies in the flask. Medium was decanted and cells were washed once with pre-warmed PBS. Molten agar $(2 \mathrm{ml}, 0.6 \%(\mathrm{w} / \mathrm{v})$ (Difco) maintained at $40-45^{\circ} \mathrm{C}$ ) in MEM (supplemented with $5 \%(\mathrm{v} / \mathrm{v})$ FCS and $1 \%(\mathrm{v} / \mathrm{v})$ L-glutamine) was poured over the confluent layer of A549 cells. Agar at this temperature had no effect on A549 cell viability and has been used previously to immobilize a variety of cell lines [11]. The agar was allowed to set at room temperature for $15 \mathrm{~min}$ and flasks were incubated at $37{ }^{\circ} \mathrm{C}$ and $5 \% \mathrm{CO}_{2}$ in a humidified atmosphere. The response of the underlying layer of confluent cells to the growth of the proliferating fungus was monitored by microscopic examination. Control flasks consisted of confluent layers of A549 cells overlaid with molten agar as above. Cells in control flasks remained attached for up to $72 \mathrm{~h}$. A diagrammatic representation of the soft agar assay is presented (Fig. 1).

\section{Propidium iodide (PI) and annexin-V (AV) staining}

The mode of cell death occurring in the soft agar assay was monitored using the DNA staining agent PI [13] and the phosphatidylserine binding agent AV Fluos [14]. The method used to stain A549 cells embedded in the soft agar was a modification of that described previously for cultured cells $[15,16]$. Cells were stained by applying $100 \mu \mathrm{l}$ of labelling solution $(1000 \mu \mathrm{l}$ of incubation buffer [10 mм Hepes/NaOH, pH 7.4, $140 \mathrm{~mm} \mathrm{NaCl,} 5 \mathrm{~mm}$ $\mathrm{CaCl}_{2}$ ] containing $20 \mu \mathrm{l}$ of $50 \mu \mathrm{g} \mathrm{ml}^{-1} \mathrm{PI}$ (Sigma) and/ 
Fig. 1 Schematic representation of the soft agar assay. Conidia of $A$. fumigatus were allowed to adhere to A549 cells for $2 \mathrm{~h}$ and were then immobilized using a thin layer of soft agar $[0.6 \%(\mathrm{w} / \mathrm{v})]$. Following the germination of conidia, the resulting colony was entrapped in the layer of agar above the A549 cells.

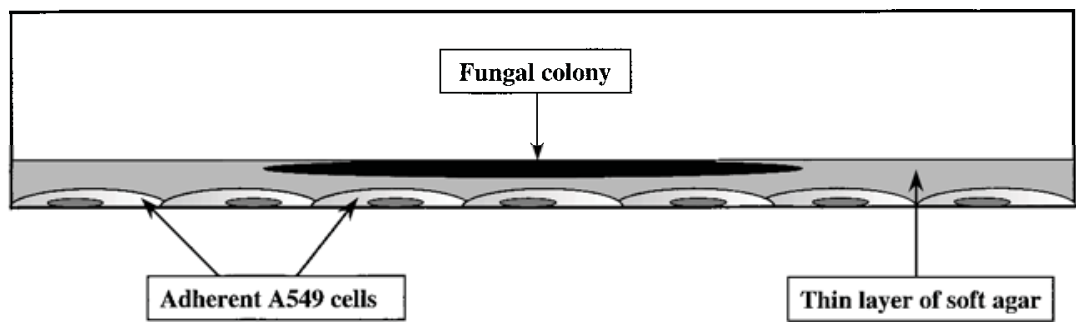

or $20 \mu \mathrm{l}$ of AV-Fluos (Boehringer, Mannheim, Germany)) to the surface of the agar. Stains were allowed to absorb for $15 \mathrm{~min}$ before examination by fluorescence microscopy using a Leitz Diaplan microscope under UV light. AV and PI fluorescence was evaluated using $488 \mathrm{~nm}$ for excitation and $515 \mathrm{~nm}$ long-pass filter for detection.

\section{Detection of toxic metabolites in zones of cell detachment using thin-layer chromatography (TLC)}

Agar (1 g wet weight) was cut using a sterile surgical scalpel from zones of cell detachment around fungal colonies grown for $30 \mathrm{~h}$. Samples from around 2025 zones were pooled and extracted with chloroform:methanol (2:1). In total, between four and five samples were removed from each culture flask. Control samples consisted of a similar amount of agar removed from flasks consisting of A549 cells embedded in agar. The chloroform:methanol layer was placed in a 50-ml round bottomed flask and extracted to dryness under vacuum. The residue was then dissolved in methanol and spotted $(20 \mu \mathrm{l})$ onto a $10 \times 20 \mathrm{~cm}$ silica gel 60 (Merck) glass TLC plate and developed in a toluene-ethylacetate-10\% formic acid $(5: 4: 1 \mathrm{v} / \mathrm{v} / \mathrm{v})$ solvent system. Once removed and dried, the plate was visualized on an UV transilluminator (UVP) for bands that represented known toxic metabolites due to their characteristic colour and $R_{f}$ values [17,18]. Plates were stained with $0.5 \%(\mathrm{v} / \mathrm{v})$ $p$-anisaldehyde (Sigma) in methanol:acetic acid: concentrated sulphuric acid $(17: 2: 1 \mathrm{v} / \mathrm{v} / \mathrm{v})$, incubated at $110{ }^{\circ} \mathrm{C}$ for $10 \mathrm{~min}$ and visualized under white light and UV light for the development of additional bands.

\section{Results}

The effect of A. fumigatus growth on confluent layers of A549 cells

A. fumigatus conidia were immobilized on a confluent monolayer of A549 cells in a thin layer of soft agar as described. Conidia were allowed to germinate at $37{ }^{\circ} \mathrm{C}$ and the response of cells to fungal growth was recorded microscopically.
After $16 \mathrm{~h}$, hyphae had proliferated radially and the colonies measured approximately $3.5 \mathrm{~mm}$ in diameter with no apparent effect on the underlying layer of confluent cells. When the diameter of the fungal colony reached $5 \mathrm{~mm}$, the hyphae or factors secreted by the hyphae caused the rounding up and detachment of A549 cells from the surface of the culture flask (Fig. 2). Cell detachment was first observed underneath the centre of the colony and this effect gradually spread to the regions around the hyphal tips. After $22 \mathrm{~h}$ incubation the fungal colonies measured approximately $7.5 \mathrm{~mm}$ and A549 cells rounded up and detached $1.5-2 \mathrm{~mm}$ ahead of the hyphal tips. This eventually resulted in the appearance of a broad zone or 'halo' of cell detachment around the fungal colony (Fig. 3). Detached cells clumped together giving a 'grainy' appearance to the zone of cell detachment. After $30 \mathrm{~h}$ incubation the area of cell detachment was twice that of the area of the fungal colony (Fig 4). Control A549 cells showed no signs of cell detachment or death following a similar incubation period.

Agar ( $0.1 \mathrm{~g}$ wet weight) from the zones of A549 cell detachment around fungal colonies was placed onto sterile filter discs (Gelman, MI, USA) cut into $25-\mathrm{mm}^{2}$ squares and incubated for $20 \mathrm{~min}$ at $37^{\circ} \mathrm{C}$. Agar was removed by gentle scraping from the surface of the filters

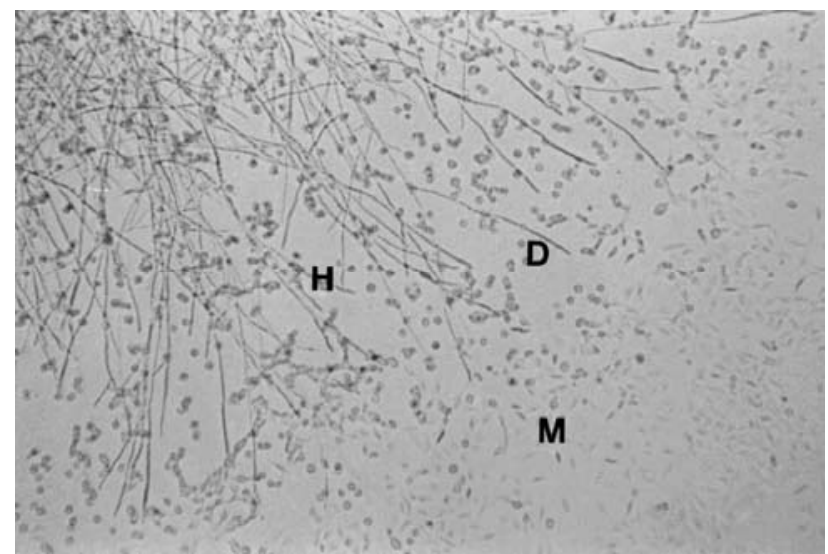

Fig. 2 Response of monolayer of A549 cells to the presence of $A$. fumigatus hyphae. The growth of hyphae of A. fumigatus $(\mathrm{H})$ above a monolayer of A549 cells (M) causes cell detachment (D) in a zone around and ahead of the edge of the colony. (Magnification $\times 200$.) 


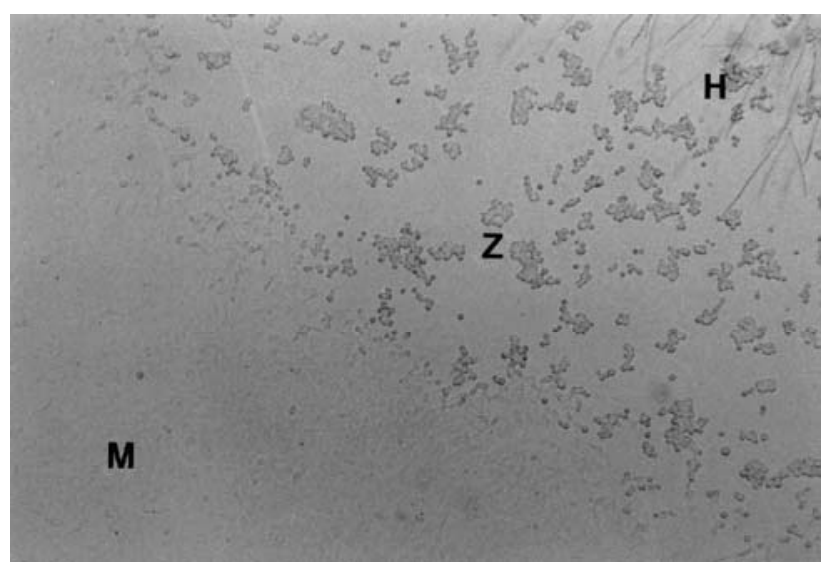

Fig. 3 Phase contrast micrograph of A. fumigatus colony embedded in a layer of soft agar and surrounded by a zone of A549 cell detachment. Conidia of $A$. fumigatus germinated within a soft layer of agar above a confluent layer of A549 cells (M). Following incubation at $37{ }^{\circ} \mathrm{C}$ and $5 \% \mathrm{CO}_{2}$ for $30 \mathrm{~h}$ a broad zone of cell detachment $(\mathrm{Z})$ is visible around the fungal colony, extending beyond the outermost hyphae $(\mathrm{H})$. (Magnification $\times 40$ ).

which were then placed on a monolayer of A549 cells. These were left in place for $2 \mathrm{~h}$ in a humidified atmosphere at $37^{\circ} \mathrm{C}$ and $5 \% \mathrm{CO}_{2}$ and then removed. The area that the filter discs covered was carefully marked during this incubation period. Complete cell detachment occurred underneath the discs and also up to 1-2 $\mathrm{mm}$ away from the edge of the discs following incubation for $2 \mathrm{~h}$. This indicated that factors involved in cell detachment were absorbed onto the filter discs and could diffuse away when subsequently placed on a monolayer of cells. Untreated discs did not cause cell detachment underneath or surrounding the perimeter of the disk following identical incubation conditions, nor was cell detachment or cell death observed when agar overlying A549 cells but not containing A. fumigatus was placed on filter disks prior to placing on monolayers of cells.

\section{Detection of the mode of cell death using PI and AV staining}

To identify potential modes of cell death occurring in A549 cells which detached around the colonies, both PI and AV staining was performed on cells after various periods of time. Cells beginning to detach underneath the outer rim of the fungal colony showed little or no PI fluorescence indicating no loss of plasma membrane integrity. However increased PI fluorescence was recorded for cells underneath the central region of the fungal colony (Fig. 5) indicating an increase in the number of cells displaying disruption of the cell membrane and the staining of DNA. The fluorescence of the PI positive cells was visible through the layer of hyphae. AV was placed on agar both as an individual fluorescent probe and in association with PI. Cells that started to show cell detachment from the surface of the flask showed no AV fluorescence, while cells that had detached for periods greater than $6 \mathrm{~h}$ were found to be positive for AV staining and also positive for AV and PI when double staining was employed.

Identification of factors secreted by $A$. fumigatus ahead of the proliferating fungus

In order to identify the agents responsible for the detachment of cells in advance of the hyphae of A. fumigatus and to establish whether detectable levels of fungal toxins were present, samples of agar from zones of cell detachment were pooled, extracted with chloroform:methanol (2:1) and spotted onto a TLC plate as described. The plate was subsequently visualized under

Fig. 4 Areas of colonies of A. fumigatus and associated zones of cell detachment. The area of $A$. fumigatus colonies and associated zones of cell detachment was determined with the aid of vernier calipers. After $30 \mathrm{~h}$ incubation at $37^{\circ} \mathrm{C}$ and $5 \% \mathrm{CO}_{2}$ the area of the zone of clearance is greater than that of the fungal colony.

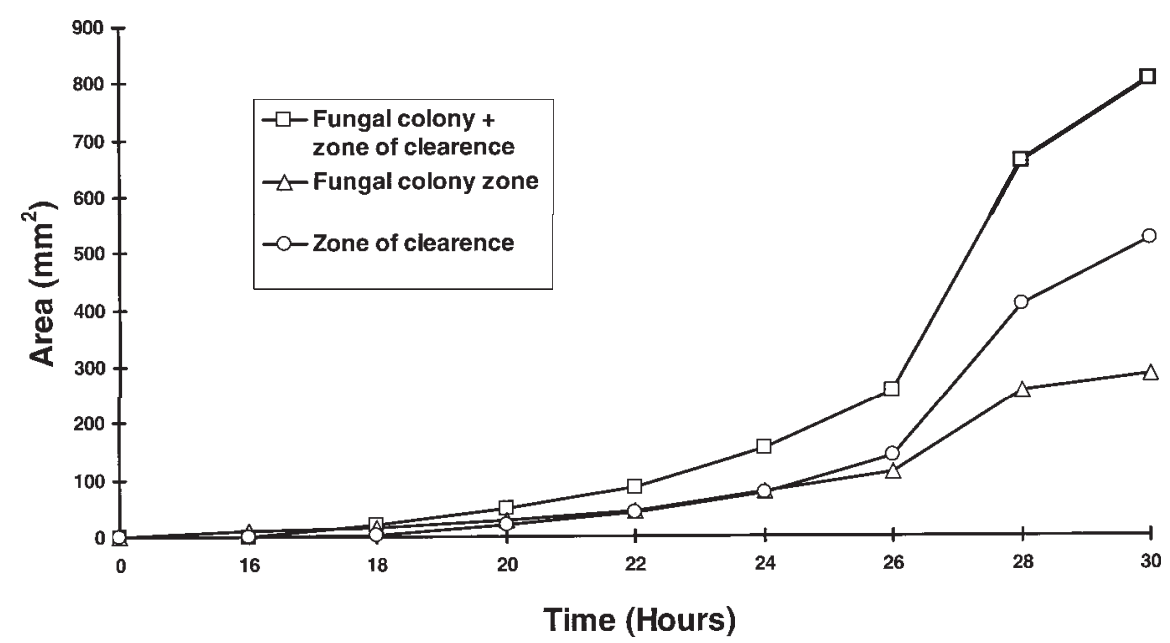




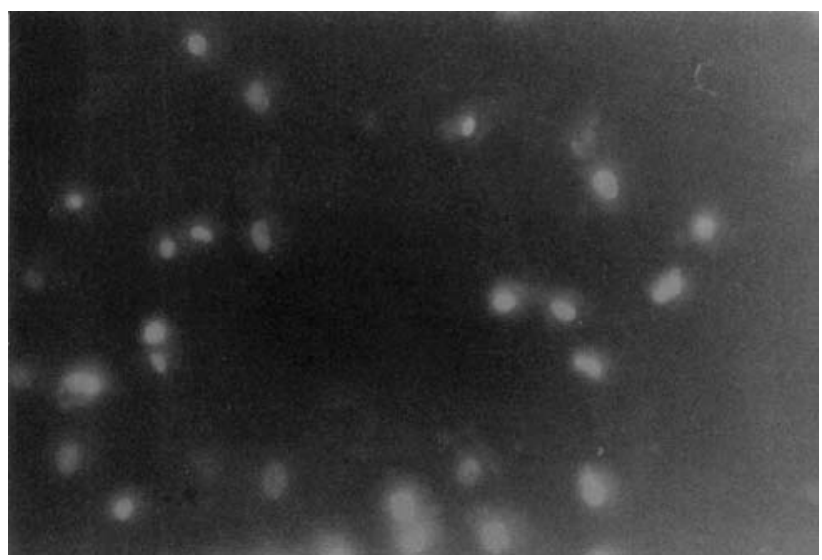

Fig. 5 Fluorescence of detached A549 cells stained with PI. A549 cells that detached underneath the central region of $A$. fumigatus colonies initially showed no fluorescence. After approximately $6 \mathrm{~h}$ incubation, cells showed PI fluorescence indicating disruption of the cell membrane and the staining of the cellular DNA. Please note that only the fluorescence of dead A549 cells is shown in this figure, the overlying fungal mycelium is not visible in this photograph. (Magnification $\times 400$.)

UV light for toxic metabolites according to their characteristic colour and $R_{f}$ values $[17,18]$.

Under UV, two light blue bands were seen at $R_{f} 42$ and $R_{f} 45$ on lanes extracted from the zones of cell detachment. After staining with $p$-anisaldehyde, a bright blue green band developed under UV $\left(R_{f} 9\right)$. These three bands were not visible when control agar was extracted. TLC analysis of standard gliotoxin, helvolic acid and fumagillin resulted in $R_{f}$ values of 42,48 and 52 respectively but did not correlate with any spots extracted from the zones of cell detachment. The agent extracted from the zone of cell detachment with an $R_{f}$ value of 42 had a colour different from gliotoxin although the $R_{f}$ value was similar. Agar from control flasks (i.e. containing immobilized $A$. fumigatus colonies but no A549 cells) was collected and extracted as described above. When this material was analysed by TLC a similar number of bands was seen as obtained above indicating that these compounds are produced by the fungus regardless of whether the target cell is present in the surrounding agar.

\section{Discussion}

Although the exact mechanisms employed by $A$. fumigatus to colonize host tissue are poorly characterized, the ability to produce toxins $[4,8,9]$ appears to be important in pathogenesis and the detachment of epithelial cells from the underlying basement membrane is a critical factor in the colonization of respiratory tissues [8,19].
In the work presented here, an in vitro model is demonstrated in which $A$. fumigatus conidia were allowed to germinate within a layer of soft agar overlying a monolayer of A549 cells. This model allows an investigation of the response of cells to the growth of a fungal colony where the fungus is maintained in close contact with the cells, simulating the conditions on the respiratory surface in patients with invasive aspergillosis and in the mucus of cystic fibrosis patients with ABPA [8].

A fungal colony diameter of $5 \mathrm{~mm}$ resulted in the rounding up of A549 cells mainly underneath the central region of fungal growth and in the vicinity of the hyphal tips. At no point were hyphae seen to penetrate cells. The amount of A549 cell detachment appeared to be dependent upon the size of the fungal colony. This was evident after $26 \mathrm{~h}$, when fungal colonies measuring $7.5 \mathrm{~mm}$ in diameter caused cells to detach $1.5-2 \mathrm{~mm}$ ahead of the outermost hyphal tips. After $30 \mathrm{~h}$ the zone of cell detachment was twice that of the area of the fungal colony implying the diffusion of enzymes or toxins through the agar above the layer of A549 cells (Fig. 4).

The depletion of nutrients from the surrounding medium by the proliferating fungus was considered as a possible explanation for the detachment of cells. Despite low levels of glucose recorded in the zones of cell detachment, two points suggest that nutrient depletion was not responsible for cell detachment. A549 cells cultured in a low nutrient environment (i.e. cells covered in a layer of soft agar $(0.6 \%(\mathrm{w} / \mathrm{v}))$ containing PBS instead of MEM culture medium) remained attached after $24 \mathrm{~h}$ growth at $37^{\circ} \mathrm{C}$. The growth of the yeast Candida albicans immobilized in a layer of soft agar above a monolayer of A549 cells caused no cell detachment after $48 \mathrm{~h}$ even though negligible nutrient levels were present in the vicinity of the yeast colonies.

Two forms of mammalian cell death exist (i.e. necrosis and apoptosis) with distinct biochemical and morphological characteristics. The main irreversible feature of necrotic cell death is the loss of plasma membrane integrity and function that can easily be detected using the DNA staining agent PI [15]. Cells undergoing apoptosis participate in their own demise by following a specific programme of events activated in the dying cell which include cell detachment, nuclear fragmentation and apoptotic body formation [13,20]. During the early stages of apoptosis phosphatidylserine (PS), which is normally located on the inner leaflet of the plasma membrane facing the cytosol, becomes externalized due to action of a flippase [14]. This can be detected using $\mathrm{Ca}^{2+}$ dependent phospholipid-binding protein $\mathrm{AV}$, which has a high affinity for PS $[14,16]$. Apoptotic cells are positive for AV staining due to the externalization of 
PS. Necrotic cells stain positive for PI due to DNA breakdown but are also AV positive due to the staining of internal PS exposed following cell rupture [21].

A549 cells detaching at the outer rim of the fungal colony initially showed little PI or AV fluorescence. Elevated PI fluorescence was recorded in cells detached for periods greater than $6 \mathrm{~h}$ towards the centre of the colony indicating an increase in the number of cells dying by necrosis due to the rupture of the cell membrane and the staining of nuclear DNA. Detached cells underneath the centre of the fungal colony were double positive for $\mathrm{AV}$ and PI indicating cell death by necrosis.

Extraction and analysis by TLC of agar from zones of cell detachment around $A$. fumigatus colonies revealed the presence of three metabolites with $R_{f}$ values of 9,42 and 45. These do not correspond to any of the wellcharacterized toxins of $A$. fumigatus (except for gliotoxin, $R_{f}=42$, which was a different colour from the compound described in this paper) $[17,18]$ and efforts to characterize them are ongoing. Agar extracted from around $A$. fumigatus colonies grown in the absence of A549 cells contained the compounds described, indicating that their production is not dependent upon the presence of a monolayer of cells.

The work presented here indicates that colonies of A. fumigatus produce factors that diffuse in advance of the hyphal tips causing cell detachment and death. Cell detachment appears as a zone or 'halo' around each colony in the model described here, and death appears to be exclusively by necrosis. Previous work by our group has indicated that growth medium conditioned by A. fumigatus is capable of initiating cell death by apoptosis but that secondary necrosis invariably results [22]. The soft agar model developed here allows the visualization of the response of cultured cells to the effects of fungal growth and the secretion of toxic agents. It may provide a more realistic model of conditions in the lung in invasive aspergillosis and in the pulmonary secretions of cystic fibrosis patients with ABPA than is provided by any in vitro system applying conditioned medium to monolayers of cells.

Using this system, it should prove possible to discern differences in the production and secretion of toxic agents by pathogenic and non-pathogenic isolates of Aspergillus species. A soft agar system for immobilizing fungal colonies has a number of advantages including: (i) less diffusion of toxins away from the fungal colony and target cells than occurs in growth in liquid medium; (ii) allowing investigation of the mechanism by which A. fumigatus causes cell detachment in surrounding cells; (iii) possible modification to allow screening for A. fumigatus mutants deficient in toxin production and (iv) possible adaptation for use in studying the response of other cultured cell lines or pulmonary tissues to the growth of $A$. fumigatus or other pathogenic fungi.

\section{References}

1 Gerson SL, Talbot GH, Hurwitz S, Strom BL, Lusk EJ, Cassileth PA. Prolonged granulocytopenia: the major risk factor for invasive pulmonary aspergillosis in patients with acute leukemia. Ann Int Med 1984; 100: 345-351.

2 Sutton $\mathrm{P}$, Newcombe NR, Waring $\mathrm{P}$, Müllbacher A. In vitro immuno-suppressive activity of gliotoxin, a metabolite produced by human pathogenic fungi. Infect Immun 1994; 62: 1192-1198.

3 Denning DW. Aspergillosis: diagnosis and treatment. Int J Antimicrob Agents 1996; 6: 161-168.

4 Amitani R, Murayama T, Nawada R, et al. Aspergillus culture filtrates and sputum sols from patients with pulmonary aspergillosis cause damage to human respiratory ciliated epithelium in vitro. Eur Respir J 1995; 8: 1681-1687.

5 Tomee JFC, Wierenga ATJ, Hiemstra PS, Kauffman HF, Proteases from Aspergillus fumigatus induce release of proinflammatory cytokines and cell detachment in airway epithelial cell lines. J Inf Dis 1997; 176: 300-303.

6 DeHart DJ, Agwu DE, Julian NC, Washburn RG. Binding and germination of Aspergillus fumigatus conidia on cultured A549 pneumocytes. J Infect Dis 1997; 175: 146-150.

7 Tronchin G, Esnault K, Renier G, Filmon R, Chabasse D, Bouchara JP. Expression and identification of a laminin-binding protein in Aspergillus fumigatus conidia. Infect Immun 1997; 65: 9-15.

8 Fraser RS. Pulmonary aspergillosis: pathologic and pathogenetic features. Pathol Annul 1993; 28: 231-277.

9 Müllbacher A, Waring P, Eichner RD. Identification of an agent in cultures of Aspergillus fumigatus displaying anti-phagocytic and immunomodulating activity in vitro. J Gen Microbiol 1985 131: $1251-1258$.

10 Mitchell CG, Slight J, Donaldson J. Diffusible component from the spore surface of the fungus Aspergillus fumigatus which inhibits the macrophage oxidative burst is distinct from gliotoxin and other hyphal toxins. Thorax 1997; 52: 796-801.

11 Carey BM, Dooley M, Weedle R, Clynes M. Production of autostimulatory growth factors by the human carcinoma line, RPM 2650. In Vitro Cell Dev Biol 1992; 29: 153-160.

12 Lieber M, Smith B, Szakal A, Nelson-Rees W, Todaro GA. Continuous tumour-cell line from a human lung carcinoma with properties of type II alveolar epithelial cells. Int J Cancer 1976; 17: $62-70$.

13 Dive C, Gregory CD, Phipps DJ, Evans DL, Milner AE, Wyllie AH. Analysis and discrimination of necrosis and apoptosis (programmed cell death) by multiparameter flow cytometry. Biochem Biophys Acta 1992; 1133: 275-285.

14 Vermes I, Haanen C, Steffens-Nakken H, Reutelingsperger C. A novel assay for apoptosis. Flow cytometric detection of phosphatidylserine expression on early apoptotic cells using fluorescein labelled Annexin V. J Immunol Meth 1995; 184: 39 51.

15 Allen T, Hunter WJ, Agrawal DK. Morphological and biochemical characterization and analysis of apoptosis. $J$ Pharmac Toxicol Methods 1997; 37: 215-228.

16 Martin SJ, Reutelingsperger CPM, Rader JA, van Schie RC, LaFace DM, Green DR. Early redistribution of plasma membrane phosphatidylserine is a general feature of apoptosis regardless of the initiating stimulus: inhibition by over expression of Bcl-2 and Abl. J Exp Med 1995; 182: 1545-1556. 
17 Paterson RR. Standardized one- and two-dimensional thin-layer chromatographic methods for the identification of secondary metabolites in Penicillium and other fungi. J Chrom 1986; 368: 249-264.

18 Frisvad, JC, Thrane U. Standardized high performance liquid chromatography of 182 mycotoxins and other fungal metabolites based on alkylphenone retention indices and UV-vis spectra (diode array detection). J Chrom 1987; 404: 195-214.

19 Venaille TJ, Mendis HW, Warton A, Walker L, Papadimitriou JM, Robinson BWS. Study of human epithelial cell detachment and damage: development of a model. Immunol Cell Biol 1989; 67: 359-369.

20 Cohen JJ. Overview: mechanisms of apoptosis. Immunol Today 1993; 14: 126-130.

21 Darzynkiewicz Z, Juan G, Li X, Gorczyca W, Murakami T, Traganos F. Cytometry in cell necrobiology: analysis of apoptosis and accidental cell death. Cytometry 1997; 27: 1-20.

22 Daly P, Verhaegen S, Clynes M, Kavanagh K. Culture filtrates of Aspergillus fumigatus induce different modes of cell death in human cancer cell lines. Mycopath 1999; 146: 67-74. 